\title{
The effectiveness of headache treatment using manual therapy techniques according to the Brian Mulligan concept
}

\author{
Piotr Szomiński ${ }^{1}$, Dominika Bacz ${ }^{1}$ \\ ${ }^{1}$ Cracow Higher School of the Health Promotion, Cracow, Poland \\ Correspondence to: Piotr Szomiński, piotrszominski@gmail.com \\ DOI: https://doi.org/10.5114/for.2021.106946
}

Received: 11.02.2021 Reviewed: 27.02.2021 Accepted: 27.02.2021

\begin{abstract}
Aims: The primary aim of this study was to assess the effect of manual therapy techniques according to the Mulligan concept on treating headache. The secondary aim was a theoretical presentation of headache types, diagnostic methods and alternative forms of treatment. We also present the principles of the concept and the underlying techniques used in this study.
\end{abstract}

Key words manual therapy,

Mulligan concept, headache, treatment, diagnosis, quality of life

Material and methods: The study participants were 27 individuals of different ages, both male and female, who experienced headache. The subjects were diagnosed using the author's examination card to evaluate therapeutic effects and the World Health Organization Quality of Life Instrument, Short Form (WHOQOL-BREF) questionnaire to assess patients' quality of life before and after therapy.

Results: Of the 27 patients included in the study, 10 experienced immediate improvement, with complete relief of their headaches. Seven patients showed improvement, but their headaches did not disappear completely. The patients' quality of life increased after the treatment, and the analgesic effect of the manual therapy was maintained for up to four weeks.

Conclusions: Manual techniques from the Mulligan concept are effective in the treatment of cervicogenic headaches. The intensity of pain in patients decreased after therapy and remained at a lower level for at least four weeks. The exercises performed by the patients as part of self-therapy reduced their headaches, and the patients' quality of life was higher after therapy. 


\section{Introduction}

Pain is a phenomenon that people experience almost every day. It is a form of warning information about adverse effects or beginning or ongoing disease processes in the body [2]. Pain is defined as 'all sorts of unpleasant physical or mental sensations, sensations indicative of some insufficiency, disturbance in the functioning of the body or damage to it'. One of the most common symptoms is headache. According to the World Health Organization (WHO), headaches affect nearly $50 \%$ of the population worldwide, of which $30 \%$ have experienced a migraine at least once a year, posing a significant problem in daily functioning. The most common form of headache treatment is pharmacotherapy, which relieves pain but does not treat the cause [5].

Contemporary medicine distinguishes between many forms of therapy to eliminate pain by targeting the underlying cause. Accurate diagnosis is the key to solving the problem. For this purpose, anamnesis, clinical tests and diagnostic examinations are carried out. The treatment is also aided by making the patient aware of the cause and, sometimes, of the severity of the problem. Diagnosis allows for a complex and, above all, targeted therapy, which does not have to consist only of pharmacotherapy. One form of pain treatment, less well known in society, is manual therapy, which was developed by Brian Mulligan. This method uses therapeutic techniques and passive or active movement in the localised problem area $[3,8,9]$.

The effectiveness of the therapy has been confirmed by results in the form of reduced pain levels. Thanks to the conferences where the concept is popularised, it is gaining more importance and trust from both therapists and patients.

\section{Aims}

The primary aim of this study was to evaluate the effectiveness of the therapeutic techniques within the manual therapy concept (developed by Brian Mulligan) in the treatment of headache. The secondary aim was to describe the theoretical aspects of headache, its types, causes, diagnostic methods and forms of treatment. The principles of the concept and therapeutic techniques used in the treatment of cervicogenic headaches in this study are also presented.

\section{Materials and methods}

The study involved 27 people aged between 19 and 37 , both men and women. All of them were residents of Kraków (Poland) and employees of one of the companies in this city. The subjects worked mainly at the computer and reported tension-type headaches or migraine headaches. All participants were informed about the aim and course of the study and signed a consent form, which was voluntary and anonymous.

The patients were treated as needed with the following techniques: sustained natural apophyseal glide (SNAG) for headache, reverse SNAG for headache, upper cervical traction and the SNAG technique combined with rotation at the $\mathrm{C} 1-\mathrm{C} 2$ level. All 27 instructed patients were asked to continue the individually selected techniques at home. Patients performed the following techniques as self-therapy: SNAG for headache, reverse SNAG for headache, upper cervical self-traction and SNAG at the C1-C2 level combined with spinal rotation $[3,8,9]$. The therapist was in regular contact with the patients and advised if there were problems performing the techniques.

The subjects were diagnosed using the author's examination card to evaluate therapeutic effects and the World Health Organization Quality of Life Instrument, Short Form (WHOQOL-BREF) questionnaire to assess patients' quality of life before and after therapy. Statistical analysis of quality of life in its various aspects was performed using the arithmetic mean, dominant, median, standard deviation, Shapiro-Wilk normality of distribution test and Wilcoxon test. Microsoft Office Excel 2010 was used to analyse the obtained results, which were subsequently presented in tables and graphs. 
The study consisted of two stages. The first stage included diagnosis using the authorised examination survey and assessing quality of life with the WHOQOL-BREF questionnaire and the performance of the treatment techniques of the Mulligan concept. After the applied treatment, the immediate effects of the therapy were evaluated. The second stage of the study occurred four weeks after the therapy and comprised only an examination using the WHOQOL-BREF questionnaire and an interview to determine the long-term effects of therapy with a control measurement of pain using the visual analogue scale (VAS). A total of three measurements of pain intensity were taken: before therapy, immediately after therapy and four weeks after therapy.

The author's examination card was developed to diagnose and treat headaches using Mulligan manual therapy techniques. The card consists of a diagnostic and a therapeutic section. The diagnostic section includes questions about the patient's personal information, such as name, gender, address, phone number, age, education, occupation and hobbies. One of the questions concerns the initial medical diagnosis received by the patient prior to the study. The second section of the chart contains the questions necessary to make a correct diagnosis and choose an appropriate therapy technique. This section was divided into the patient's primary problem and the symptoms accompanying the pain. The therapist projected the pain onto a head map located on the first page of the examination card. An essential part of the diagnostic section was the history of previous headache treatment, intensity and previous therapeutic management to reduce or eliminate the headache.

The second research tool was the short version of the WHOQOL-BREF questionnaire, which assesses quality of life at the somatic, psychological, social and environmental levels. The aim was to determine how the reduction or elimination of headaches affects quality of life. The respondents answered 26 questions, 2 of which did not belong to any of the above domains. The analysis of the results was performed according to the key assigned to the questionnaire, and the raw scores were converted into $\mathrm{B}$ and $\mathrm{C}$ scores according to the guidelines given in the WHOQOL-BREF manual $[4,6]$. A total of 54 questionnaires were returned for analysis

\section{Results}

The majority of the respondents were women (n $=20,74 \%)$, and the rest were men $(n=7,26 \%)$. The average age of the respondents was 25 years. The median age was 24 years, and the dominant age was 19 years. Based on the examination card, hypertension due to prolonged stress was found in almost one-fourth of the cohort; diabetes mellitus in two patients; surgery not necessarily affecting headache complaints, such as appendectomy and cholecystectomy, in three subjects and comorbidities (such as diabetes mellitus, hypertension and migraine) that may cause symptoms or interfere with the treatment process in more than $40 \%$ of the group. According to the initial medical visits, $92.5 \%$ of the subjects had a tension-type headache and two had a migraine headache. Twenty-five subjects indicated the forehead and temporal regions as areas of tension pain. One person (8\%) also reported pain in the parietal area. The vast majority stated that the pain often occurred during computer work and was relieved after taking pharmacological agents. There were no differences in headache symptoms and frequency of occurrence between the patients with migraines and those with tension headaches, except for the inability to function normally during pain. After diagnosis, treatment was applied according to each patient's problem. $\mathrm{Pa}-$ inless techniques were used in all patients. Each technique was repeated three times.

After treatment, the patients were retested using the VAS. Of the 27 subjects included in the study, 10 (37\%) experienced immediate improvement with complete headache relief. In 7 patients (26\%), improvement was observed, but the headache was not completely resolved. The remaining group of participants showed no improvement, and pain remained at a similar level as before therapy. The patients with migraine headaches were part of the group in which no positive effects of therapy were observed. 
Statistical analysis revealed a mean headache score of 5.074 before therapy and 3.074 after therapy. The median decreased by 2 points, from 5 before therapy to 3 after therapy. A significant change in dominance, from 5 to 0 , can also be observed. The lower and upper quartiles were Q1 = 4 and Q3 = 0, respectively. After therapy, Q1 and Q3 were both equal to 6. The control examination showed significant improvement. Pain complaints did not occur throughout the treatment period in 8 patients (30\%). Of these 8 patients, 5 experienced similar results after the first round of therapy. The number of remaining patients whose complaints decreased over time increased by more than $100 \%$ compared to the first assessment. Of the 10 patients with no immediate effect, $6(22 \%)$ reported a significant reduction in pain. After four weeks of therapy, 2 patients reported no changes in their pain levels. Of the 27 patients undergoing therapy, 2 patients, representing $8 \%$ of the subjects, stated that their complaints worsened. The Shapiro-Wilk normality test showed that the distribution of the pain intensity measurements was not close to normal $(p>0.05)$; therefore, the non-parametric test-Friedman analysis of variance-was used to analyse the significance of differences. The severity of pain experienced by the subjects differed significantly between the three measurements taken $\left(x^{2}(2)=30.82 ; \mathrm{p}<\right.$ $0.0001)$. The Wilcoxon test indicated that pain intensity was significantly higher before therapy (M $=5.07 ; \mathrm{SD}=1.73$ ) than immediately after therapy $(\mathrm{M}=3.07 ; \mathrm{SD}=2.97 ; \mathrm{p}<0.0003)$ and four weeks after therapy $(\mathrm{M}=2.96 ; \mathrm{SD}=2.88 ; \mathrm{p}<.00014)$. The pain level experienced immediately after therapy was not statistically significantly different from that measured four weeks after therapy ( $p$ $=.05614)$ (Figure 1).

The results based on the WHOQOL-BREF questionnaire began with an analysis of the first two separate questions on quality of life. Before starting therapy, $66 \%$ of the subjects were satisfied with their lives. A similar percentage was found when considering satisfaction with the state of their health: $55 \%$ of the subjects were satisfied. One person described their health as very unsatisfactory. Most responses oscillated around
Pain: expected marginal means Current effect $F(2,52)=16363, p=.00000$ Decomposition of active hypotheses Vertical bars indicate 0.95 confidence interval

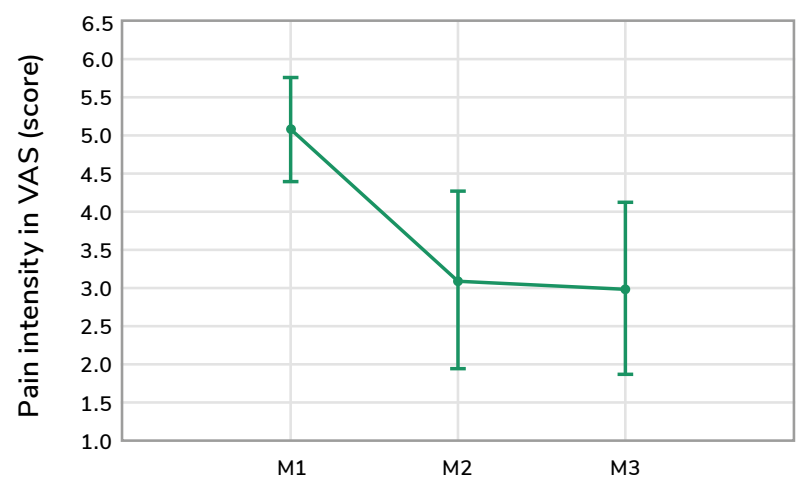

Figure 1. Analysis of headache complaints from three measurements

Legend: M - measurement, VAS - visual analogue scale, $\mathrm{p}$ - level of statistical significance

a score of satisfied or very satisfied. Four weeks after therapy, satisfaction with life improved, with respondents indicating a scale of answers above 3. Based on the mean analysis, it is concluded that the patients' quality of life increased by almost 0.3 points.

The quality of health of the subjects also improved by more than 0.5 points when analysing the arithmetic mean. Questions 3, 4 and 18, which related to daily pain, dependence on daily pharmacotherapy and functioning at work, had the most significant impacts on the results. After four weeks, the questionnaire results indicated that the quality of life of the patients treated with Mulligan therapy improved in the somatic and psychological sections, while the social and environmental aspects of the subjects were not significantly improved.

The statistical analysis of quality of life indicated that a difference was evident in the somatic domain between the first $(M=64.07 ; \mathrm{SD}=12.75)$ and second measurements $(\mathrm{M}=66.81 ; \mathrm{SD}=12.91)$. The difference is statistically significant $(\mathrm{z}=3.0594$; $\mathrm{p}<.05)$. The mean $\mathrm{C}$ score differed by more than two percentage points ( $\mathrm{z}=64.07$ vs. 66.81$)$. Comparing the two scores (pre- and post-treatment), 
the median and dominant scores had the same value of 63. The first quartile pre- and post-test had an identical value of 56, and the top quartile Q3 changed from 75 to 81 . The minimum score changed from 38 to 44, and the maximum score changed from 81 to 88 . Quality of life in the psychological domain was statistically significantly higher after therapy $(\mathrm{M}=43.52 ; \mathrm{SD}=6.06)$ than before therapy $(\mathrm{M}=41.93 ; \mathrm{SD}=5.66 ; \mathrm{z}=-2.3664 ; \mathrm{p}<.05)$. The mean score changed from 41.92 to 43.53 . The median and dominant scores in the survey did not change, remaining equal to 44 . The lower quartile in both measurements was identical at 38; similarly, the upper quartile did not change in value. The minimum and maximum scores in both measurements remained unchanged and equal to 31 and 56, respectively. No statistically significant difference was observed in quality of life in the social and environmental domains between the first and second measurements.

\section{Discussion}

Headache management can take many forms. It can include pharmacotherapy, massage, trigger point therapy and other methods. In a case study of a 17-year-old patient with a cervicogenic headache, Kochański et al. [7] used Mulligan concepts, including the SNAG technique with its unique biomechanical effect of prolonged spinal mobilisation (C2 spinal mobilisation). The result was the complete and long-term relief of headache, which had persisted for more than a year previously. In our study, we obtained a similar result-the analgesic effect of the SNAG technique lasted for at least four weeks.
Mohamed et al. conducted a study on 48 patients with cervicogenic headache [1]. The subjects were divided into three groups: the first (A) was treated with SNAG techniques for headache, the second (B) with SNAG $\mathrm{C} 1$ and $\mathrm{C} 2$ rotation and group (C) with combined techniques. The study used the 6-item Headache Impact Test (HIT-6), $\mathrm{C} 1$ and $\mathrm{C} 2$ rotational range of motion assessments and the Dizziness Handicap Inventory (DHI). The techniques used in this study were effective in reducing cervicogenic headache and dizziness in all groups, with more significant improvement in group $\mathrm{C}$, in which combined techniques were used. In the present study, the techniques used in the treatments were selected based on anamnesis (clinical interview), tests and patient cards. The selected Mulligan concept techniques had to be painless for the patient. After the first round of therapy, the initial analgesic effects were noticeable and persisted until the next visit.

\section{Conclusions}

Manual techniques based on Brian Mulligan's concept are effective in the treatment of cervicogenic headache. Pain intensity was significantly lower immediately after therapy and was maintained at a lower level for up to four weeks after intervention. The use of home exercises as part of self-therapy also reduced the intensity and frequency of headache episodes. After the applied therapy, the patients' quality of life was statistically significantly higher in the somatic and psychological domains. 


\section{References}

1. Mohamed AA, Shendy WS, Semary M, Mourad HS, Battecha KH, Soliman ES, et al.: Combined use of cervical headache snag and cervical snag half rotation techniques in the treatment of cervicogenic headache. J Phys Ther Sci. 2019, 31(4); 2019.

2. Domżał MT. Ból przewlekły - problemy kliniczne i terapeutyczne. Pol Przegl Neurol. 2008, 4 (1): 1-8.

3. Hing W, Hall T, Vicenzino B, Rivett DA, Mulligan B. Terapia Manualna metodą Mulligana - techniki terapeutyczne. Wydawnictwo Edra Urban \& Partner, Wrocław 2017.

4. World Health Organization. WHOQOL-BREF: Introduction, Administration, Scoring and Generic Version of The Assessment, Geneva, Switzerland 1996. Available at: https://www.who.int/mental_ health/media/en/76.pdf

5. World Health Organization. Fact Sheets: Headache disorders, 2016. Available at: https://www.who.int/ news-room/fact-sheets/detail/headache-disorders
6. World Health Organization. The World Health Organization Quality of Life (WHOQOL)-BREF - Polish translation by Baran-Furga H, Habrat B, Steinbarth-Chmielewska K, Śliwa L. 2004. Available at: https://www.who.int/substance_abuse/research_tools/en/polish_whoqol.pdf

7. Kochański B, Kałużna A, Kałużny K, Smuczyński W, Hagner-Derengowska M, Zukow W, Hagner W. Application of Brian Mulligan manual therapy method in headache treatment - case study. J Educat Health Sport. 2016, 6 (1): 101-106.

8. Mulligan B. Samodzielne leczenie dolegliwości pleców, szyi i kończyn. Wydawnictwo Poligrafix, Kraków 2008.

9. Mulligan B.: Terapia Manualna techniki "Nag”, „Snag”, „MWM”. Wydawnictwo Poligrafix, Kraków 2016. 